\title{
Understanding Military Families Who Have Dependents with Special Health Care and/or Educational Needs
}
Abstract Word Count $=250$
Complete Word Count $=3,705$
Number of References $=37$
Number of Tables $=7$
Number of Figures $=0$ 


\begin{abstract}

\section{Background}

Little is known about military families who have a dependent with special health care and/or educational needs. The Exceptional Family Member Program (EFMP) is designed to link these families to military/community support services through family support provider (FS providers).
\end{abstract}

\title{
Objective
}

The aim of this study was to understand FS providers' perspectives on the kinds of current challenges the families with whom they work face. This is the first study to ascertain the perspectives of professionals FS providers.

\section{Methods}

FS providers $(\mathrm{N}=160)$ completed a survey either on the phone or via the web. The survey consisted of four areas regarding EFMP: (1) background information; (2) caseload and work composition; (3) perceptions of Military Family needs; and (4) adequacy of community support services.

\section{Results}

The most commonly encountered diagnoses in military families were Autism (94\%) and Attention-Deficit Hyperactivity Disorder (93\%). Between 80\% and 90\% of FS providers reported working with families dealing with Emotional/Behavioral Disorders, Speech \& Language Disorders, Asthma, Developmental Delays, and Mental Health Problems. FS providers noted that relocations are particularly challenging for military families in the EFMP.

\section{Conclusions}

Training and programming of social service professionals working with military families who have a dependent with special health care and/or educational needs should focus on commonly occurring challenges seen in this population. As much as possible, FS providers should be familiar with evidence-based programs and practices designed to address these pressing problems. The process and execution of relocations should be streamlined so as to enhance continuity of care. 


\section{Introduction}

One of the most challenging life events in families is having a child or loved one with special healthcare and/or educational needs ${ }^{1}$. There are approximately 220,000 active duty and reserve Service Members who have a family member with needs ${ }^{2}$. Only a few studies of military families who have children with special healthcare and/or educational needs have been conducted. In a survey study of 253 families, they reported poorer health and greater difficulties coping with job demands compared to families who did not have children with special healthcare and/or educational challenges ${ }^{3}$. Military families having a child with these types of needs also reported higher depressive symptoms, poorer coping, fewer favorable perceptions of their military skills and abilities, and more pessimistic attitudes about their military careers ${ }^{4}$. Although not examined in the military family context, the demands of parenting a child with special healthcare and/or educational needs has been linked to increased difficulty maintaining employment continuity ${ }^{5}$ and single parenthood and low-income appear to exacerbate these challenges ${ }^{6}$. Combining these concerns with the unique challenges of military life may make it that much more difficult to achieve resilience.

All military families are highly mobile, which has the potential to interrupt needed services for family members who have special healthcare and/or educational needs ${ }^{7}$. These service interruptions may create added stress to the family over and above the typical amount of stress that is linked to relocation. Military families must negotiate the entry of their child with special healthcare and/or educational needs into new schools, locate new clinical providers to address health issues, and connect with relevant community service agencies. 


\section{Exceptional Family Member Program (EFMP)}

The 2010 National Defense Authorization Act (NDAA) mandated the creation of a program to support military families who have children or adult dependents with special healthcare and/or educational needs. Key provisions of the act included: (a) assigning military personnel to locations where specialty care is available; (b) timely and accurate evaluations; (c) providing an adequate number of case managers; (d) improved individual services plan; and (e) support for referrals and services.

The Exceptional Family Member Program (EFMP) is a mandatory enrollment program designed to address NDAA. EFMP identifies military families who have adult or child dependents that (1) require special healthcare services; (2) receive ongoing medical services from specialists; (3) have significant behavioral health concerns; or (4) receive early intervention or special education services. EFMP professionals document these needs and link families to comprehensive support services. The need for specialized services is strongly considered in the Service Member's future job assignments as appropriate medical and educational services may be limited in some areas. EFMP balances the demands of the Military and the Service Member's career aspirations ${ }^{8}$. EFMP family support (FS) providers are the primary contact to families in the program. FS providers help families become more knowledgeable and empowered in the care of their family member. They provide information and referral services, non-medical case management, and other forms of support (e.g., sponsoring family support groups). These supports are particularly important in relocations as locating and navigating social service programs can be difficult. 
It is estimated that approximately 120,000 families are enrolled in EFMP, and the approximately two-thirds are children and youth ${ }^{2}$. According to the DoD, dependent children range in age from birth to 21-years old. Military-connected children comprise nearly two-thirds of all military dependents. Thus, the proportion of children enrolled in EFMP is consistent with the overall proportion of child dependents in the military. The remaining third of families includes those with older dependents including adult children and spouses.

\section{Current Study}

The aim of this study was to understand FS provider perspectives on the kinds of challenges military families face in meeting the special healthcare and/or educational needs of their dependents, other challenges military families faced, and the adequacy of community services and supports. We anticipated that FS provider would report encountering families who contend with a range of stressors in numerous life domains ${ }^{9}$. It is important to note, that we do not know with certainty the proportion of FS providers participating in this study who provided services to families with child or adult dependents. Family demographic questions were not permitted on the survey to assure participant confidentiality.

\section{Method}

\section{Participants}

Each FS providers $(\mathrm{N}=323)$ was emailed and invitation by the Department of Defense, Office of Community Support for Military Families with Special Needs (OSN), and Military Community and Family Policy to participate in web-based survey. Emails bounced back for 45 potential participants. Thus, email invitations were successfully sent 
to 278 FS providers. Of these, 160 FS providers responded to the survey with 146 completing the survey in its entirety. This represented a total response rate of 52.5 percent, which is favorable when compared to a recent military employee survey ${ }^{10}$.

Respondents’ demographics are shown in Tables 1-4. Each branch of the Military was represented. A goodness-of-fit test determined that the branches were represented in proportion to the overall distribution of FS providers. The sample of those who completed the survey was proportionate to the size of the branch. However, chi-square analyses revealed that response rates across the Services were not equal, $\chi 2(3, N=278)=$ $8.63 \mathrm{p}<0.05$. Follow-up analysis determined the Marine Corps FS providers responded more than expected (67.5\%), and the Army FS providers responded less than expected (46.3\%). Participants were well educated. The majority of FS providers reported working at their current position from one to five years. Only 25 percent of the FS providers had been in their current job for five or more years. However, most FS providers had worked in the field for quite some time. Nearly $50 \%$ of them had at least a decade of experience in social service provision prior to their current position.

FS providers reported working with 197 families, on average, in the prior 12 months. Thus, in an average month, FS providers interact with approximately 16 EFMP families. Although not specifically asked in the survey, it is likely that some families require a significant time investment, while others do not. For example, there are families who have dependents enrolled in the EFMP with mild and relatively straightforward conditions (i.e., Asthma) that do not require much contact with FS providers. On the other hand, some families have multiple dependents with co-morbid challenges that require substantial FS provider involvement. In addition, 21\% of respondents did not 
answer the question, which may have skewed the data for this question. It is unknown why participants did not answer the caseload question. One possibility is that they did not know the number of families and were unwilling to estimate. Of course, other possible explanations exist, including some discomfort in revealing the caseloads they carry.

\section{Measures}

The Clearinghouse for Military Readiness at Penn State University worked with the Department of Defense, Office of Community Support for Military Families with Special Needs (OSN), and Military Community and Family Policy to construct a 15- to 20-minute web-based survey. The OSN was interested in understanding the most frequently encountered types of special healthcare and/or educational needs, training needs, and the clinical decision-making processes of FS providers. The questions were developed based on discussions with OSN, review of relevant internal reports on military families with special healthcare and/or educational needs, as well as a review of relevant literature. The survey consisted of four main areas: (1) background information; (2) caseload composition; (3) professional support and development; (4) and perceptions of Military Family needs. The survey consisted of several multiple-choice (e.g., To what extent are each of the following an issue for military families?) and Likert-type scale questions (e.g., On a scale from of 1-5, to what extent do you agree that there are adequate resources in the community to assist families on my caseload?), as well as three open-ended questions (e.g., What other types of activities do you engage in while working with military families?). The multiple choice and Likert-type scale questions were analyzed using SPSS 20 and the open-ended questions were analyzed using NVivo 10 to identify common themes. 
All of the participants were sent an invitation to complete the survey via email and were given a link that would take them to the web-based survey. Two weeks following the initial invitation email a second email was sent to all non- and partialresponders asking them to complete the survey. A week after the second email was sent a third and final email reminder was sent. The survey was available to participants for a total of five weeks.

\section{Results}

\section{Types of Disabilities Encountered}

Respondents were asked to indicate whether they worked with families who were dealing with any one of 13 specific special healthcare and/or educational needs. In addition, respondents were asked to mention any other special healthcare and/or educational needs they encountered (see Table 5). Of the 13 specific disabilities cited, the largest proportion of professionals reported working with dependents with Autism and attention-deficit hyperactivity disorder (ADHD). More than 80 percent of FS providers worked with families dealing with a wide range of emotional, language, mental health, and physical health challenges. Traumatic brain injury and "other disabilities" were less commonly encountered.

Table 6 shows the average number of family cases that FS providers worked with in the prior year, by the type of disability. On average, FS providers had approximately 46 families on their caseloads dealing with Autism, 44 dealing with multiple disabilities, and 40 with ADHD. Families dealing with traumatic brain injury and "other problems" comprised only a small part of FS providers' caseloads, an average of less than five families per year. 
The survey also asked respondents to list any “other” disabilities that were not included in the list of 13. Most of the "other" disabilities were related to medical conditions (e.g., arthritis, cancer, cerebral palsy, feeding disorders, auto-immune disease, and migraine headache). Clearly, FS providers encounter a wide range of disabilities on a day-to-day basis.

\section{Other Areas of Family Concern}

To assess the broader family context and specific challenges families may face, FS providers were asked to indicate how much impact each of 12 specific challenges (e.g., educational concerns, child behavior problems, parent stress) had on military families. Table 7 reveals that out of the twelve family challenges eight were found to have, on average, an impact ranging from a "moderate extent” to "great extent." Educational concerns for children and youth were the foremost issue among families having a dependent with special healthcare and/or educational needs. On average, FS providers rated Navigating Systems (e.g., school, community or Military), Child Behavior Problems, Parent Mental Health/ Stress, Child Care Issues and Medical Problems as the next most frequent issues for families. In addition to these 12 family issues, respondents were asked to indicate the extent to which there were other issues that were not listed in the survey. These concerns included families being unsure of how to advocate for their children, parents feeling overwhelmed, lack of respite care, and problems finding clinicians who accept Military insurance (i.e., Tricare).

\section{Family Challenges Related to Relocations}

Because military families frequently relocate and these transitions are often stressful, FS providers were asked to describe common problems associated with family 
moves. The most common challenge FS providers mentioned (16\%) was a lack of continuity of care for family members with special healthcare and/or educational needs. This challenge was most related to inconsistencies in the level and type of services provided across installations and communities. Lack of continuity of care can be stressful for the families and the individual with special healthcare and/or educational needs. One respondent noted that, "Changing military doctors every three years can be very difficult especially for those EFMs in the autism spectrum.” One FS provider further explained, "Many families are afraid to leave their current accommodations to that of something unfamiliar for fear of breaking the continued plan in place for their loved one.” As a result, Service members may choose not to take on new job assignments that require relocation. There is also the specific challenge of continuity in obtaining needed medical prescriptions and equipment. One participant talked about the difficulties in inter-state relocations. "Things do not carry over from state to state. IEPs [individualized education plan] have to start all over along with trying to get assistance from the state. Because of PCS [permanent change of station] moves, our families are always at the bottom of state programs." Another elaborated, "School systems are different and what one school would do for a child with an IEP another one will not.”

Fifteen percent of FS providers stated that other challenges to continuity of care were the lack of consistency in available services, the quality of those services, and the methods used to access those services from one installation and school district to the next. As one participant stated, “There is no standard form of services. Every state and school system is different.” Identical services may not be available at the next installation, or families cannot find services comparable in scope or quality for their 
family member.

A related challenge mentioned was that the referral process can be lengthy (16\% of FS providers). "Families often have to re-apply and wait for services, for example, ABA therapy, TRICARE, and Navy Respite Care'” This leaves the family member with special healthcare and/or educational needs without needed care. As one FS provider stated, "Liaisons from other areas rarely transfer the cases to the new region in a timely manner, nor do they contact their cases as frequently. I find that those transferring in have taken it upon themselves to contact us to let us know they've moved to the area.” Thus, "warm handoffs" do not always occur.

A recurring issue that was reported was the lack of information exchange about families prior to relocations. Receiving FS providers wanted to know more about families before they arrive at a new location as this would help them support the families more effectively. As a result, some medical and educational needs are not being met and FS providers cannot provide information regarding available services and supports to families before they move. Many gaining FS providers expressed the desire to have detailed information about the specific healthcare and educational requirements of the family. A number of FS providers indicated that medical case managers should work with them to make "warm" handoffs. Respondents also indicated that answers to questions like these would be helpful: "What Special Ed is being utilized and how often? What kind of classroom set up is the child used to? Was OT [Occupational Therapy] or PT [Physical Therapy] being done during school hours?” Adequacy of Community Support Services

Respondents were also asked to assess the extent to which communities had 
adequate support services to deal with the challenges faced by military family members enrolled in EFMP on a scale from 1 = "strongly disagree" to 4 = "strongly agree.” A majority (59\%) either strongly agreed or agreed that community resources were adequate for the families on their caseload. Thus, approximately $40 \%$ either strongly disagreed or disagreed that there were adequate resources.

\section{Discussion}

Results of this study indicate that those families enrolled in the EFMP have significant healthcare and/or educational needs. Autism, developmental delays, emotional and behavioral problems were commonly mentioned by FS providers. In many cases, families have dependents with multiple special healthcare and/or educational challenges. Given the unique demands and challenges faced by all military families, it is likely that families enrolled in EFMP are at particular risk for exposure to chronic stress. Based on the observations of FS providers who work closely with military families, relocation is a highly stressful and challenging event for their families. In particular, "warm handoffs" and continuity of care are difficult to execute with high quality. Educational support services, such as IEPs are not consistently provided across school districts, and the quantity and quality of services also varies widely.

Similar concerns regarding the education of military children with special healthcare and/or educational needs were recently raised in a benchmarking study of EFMP ${ }^{11}$. In the report, FS providers indicated that one of the most frequent requests they receive is for information and advocacy for school-related problems. This is important to know given that more than 90 percent of military-connected, school-aged children are served through their local education agency (LEA) ${ }^{12}$. The high percentage of Military- 
connected students served by an LEA indicates that FS providers should get to know the local school liaison officers and make referrals. School liaison officers are familiar with their LEA's special education policies, procedures, and personnel (Aronson, Caldwell, Perkins, \& Pasch, 2011).

Beyond the schools, connections to social service agencies can be important for military families who have dependents with special healthcare and/or educational needs 14. Sixty-six percent of FS providers surveyed in this study indicated they regularly meet with community agencies. However, one-third of the professionals are not reaching out to community agencies, which may decrease the likelihood of military families accessing needed services. Local communities must also take proactive steps to reach out to military families. There are laudable examples of community capacity building to support military families across the country such as the Joint Venture Education Forum (JVEF) which is a collaborative effort between Hawaii public schools and the U.S. Pacific Command ${ }^{15}$. JVEF was created to help military family members adjust to culture and learning in Hawaii's public schools.

The integration of the community in supporting military families is made even more relevant by the varying kinds of special healthcare and/or educational needs with which families contend (e.g., autism, ADHD, emotional and behavioral problems, speech and language problems, and developmental delay). In more than 75 percent of cases, participants in this study reported working with families in which there were multiple disabilities. The findings also suggest that FS providers work with a substantial number of families. In some cases, particularly within a diverse population, service coordination may be challenging for professionals ${ }^{16}$. A multi-agency approach, where there is high 
degree of integration between and among community social service agencies ${ }^{16}$, may augment support provided by the FS providers.

Given that autism spectrum disorders (ASD) were the most frequently encountered diagnosis in this survey, it is important to note that ASD may be particularly stressful for families and may be quite distinct from other special healthcare and/or educational needs ${ }^{17}$. A recent meta-analysis found evidence of a large effect size (0.64) on family stress outcomes for having a family member with ASD compared to having a family member with Down syndrome ${ }^{18}$. Therefore, it may be particularly important that professionals working with families who have a family member with ASD to address parental stress with appropriate information and referrals that are evidence-informed ${ }^{19}$.

Another important finding in this study was the frequency with which respondents reported that families face challenges associated with the military lifestyle. The concerns of the families with whom they work go well beyond issues related specifically to their family member with a special need (e.g., financial problems, social isolation, and navigating systems of support inside and outside of the Military). A majority of respondents indicated that families contend with deployment related challenges, prolonged separations, and reintegration issues. While this finding was not surprising given prior research ${ }^{21}$, it does clearly show that military families who have a family member with special healthcare and/or educational needs may be at higher risk for feeling overburdened and taxed of their resources ${ }^{3,20}$.

Supporting military families who have a family member with special healthcare and/or educational needs is difficult and complex. Given the challenging nature of this work, there is risk for professional burnout ${ }^{21}$. The military should provide support to 
employees working in this area ${ }^{22}$. This could include training on effective case management, managing professional boundaries, and developing effective coordination. In particular, FS providers must be proficient at assisting families in finding relevant, fact-based information and providing appropriate referrals to services that are utilizing evidence-informed strategies. Therefore, it is critical that there are strong training and professional development opportunities for locating up-to-date information on special healthcare and/or educational needs and becoming knowledgeable about local resources, services, and supports for military families. Given that the provision of information and referrals is the key focus of FS providers, this professional development activity should also be reflected in the providers' typical weekly activities. While it is clear that providing service to military families who have a family member with special healthcare and/or educational challenges is a significant and challenging job, the study is encouraging in its finding that the professionals working with these families are highly educated and come to the job with relevant experience.

Even though having a family member with special healthcare and/or educational needs may increase the risk for family adjustment problems, most families do not report significant psychosocial consequences ${ }^{23}$ and most have found ways to cope ${ }^{24}$. While military families are typically resilient, few studies have examined the coping experiences of those military families who have a child with special healthcare and/or educational needs. For those families who struggle, there are evidence-based interventions focused on effective parenting, problem-solving, stress management, and other coping approaches ${ }^{25}$. For example, Triple P Positive Parenting ${ }^{26}$, Mindfulness Based Stress Reduction ${ }^{25}$, and Families Overcoming Under Stress ${ }^{27}$ are all evidence- 
based programs that have demonstrated promising effects on improving family

functioning and coping with challenging life circumstances. Professionals should become familiar with these programs, so they can make well-informed referrals for parents and families. The Clearinghouse for Military Family Readiness at Penn State University (www.militaryfamilies.psu.edu) has vetted over 950 additional programs and practices that may be of interest to practitioners working in the military context.

This study had several limitations that should be noted. It is not completely clear the proportion of EFMP dependents that were children or adults. This question could not be asked due to very strict confidentiality requirements in research with military families. Therefore, it is not clear if the respondents were referring to families who were dealing with children or adults who had medical and/or educational needs. However, the vast majority of dependents in enrolled in EFMP are children. Second, the most common diagnoses mentioned by FS providers were those that are typically diagnosed in childhood, such as Autism and ADHD. Thus, it is not unreasonable to assume that FS providers responding to the survey worked with a large number of families with child dependents in the program. Nonetheless, future studies should attempt to accurately identify the proportion of child versus adult cases with whom FS providers work. This is particularly important because services and supports differ across the developmental spectrum,

While over half of the FS providers with working email addresses responded to the survey, those working in the Army were somewhat underrepresented and those working with the Marines were slightly overrepresented. Thus, it is difficult to generalize the study findings to all FS providers. 
Finally, the survey was not designed to assess the adequacy and availability of resources within the military and civilian communities. Thus, no conclusions can be drawn regarding the quality of the EFMP and the services it provides. Future studies should focus on the quality of EFMP's implementation to identify both strengths and weaknesses. Such studies would provide important data to make any needed programmatic adjustments. Nonetheless, the study does provide information from a group of professionals working very closely with military families who have dependents with challenging medical and educational needs.

The current study highlights the EFMP and the role of the FS provider as well as the types of families they come into contact with and perceived concerns for those families. FS providers see many families with a wide range of needs. In particular, mental health problems were fairly prevalent. However, the data do not allow for an examination of whether these mental health challenges are due to the stress associated with having a dependent who requires special medical or educational care; or whether they are the result of adult mental health challenges related to the military lifestyle and/or adult psychosocial problems of an independent nature. Future studies should examine the source and mix of stresses so that targeted interventions can be used or developed. 


\section{References}

1. Segal MW, Segal DR. Implications for military families of changes in the Armed Forces of the United States. In: Caforio G, ed. Handbook of the Sociology of the Military: Springer US; 2006:225-33.

2. Wadsworth SMM. Family risk and resilience in the context of war and terrorism. Journal of Marriage and Family 2010;72:537-56.

3. Chandra A, Martin LT, Hawkins SA, Richardson A. The impact of parental deployment on child social and emotional functioning: Perspectives of school staff. Journal of Adolescent Health 2010;46:218-23.

4. Cozza SJ, Chun RS, Polo JA. Military families and children during Operation Iraqi Freedom. Psychiatric Quarterly 2005;76:371-8.

5. Hawkins SA, Schlomer GL, Bosch L, et al. A review of the impact of US military deployments during conflicts in Afghanistan and Iraq on children's functioning. Family Science 2012;3:99-108.

6. Mmari KN, Bradshaw CP, Sudhinaraset M, Blum R. Exploring the role of social connectedness among military youth: Perceptions from youth, parents, and school personnel. Child \& Youth Care Forum 2010;39:351-66.

7. de Burgh HT, White CJ, Fear NT, Iversen AC. The impact of deployment to Iraq or Afghanistan on partners and wives of military personnel. International Review of Psychiatry 2011;23:192-200.

8. Dekel R, Monson CM. Military-related post-traumatic stress disorder and family relations: Current knowledge and future directions. Aggression and Violent Behavior 2010;15:303-9. 
9. Willerton E, Wadsworth SM, Riggs D. Introduction: Military families under stress: What we know and what we need to know. Risk and resilience in US military families: Springer Science + Business Media, New York, NY; 2011:1-20.

10. Esqueda MC, Astor RA, De Pedro KMT. A call to duty educational policy and school reform addressing the needs of children from military families. Educational Researcher 2012;41:65-70.

11. Hutton JB, Roberts TG, Walker JD, Zuniga J. Ratings of severity of life events by ninth-grade students. Psychology in the Schools 1987;24:63--8.

12. Dyson LL. Response to the presence of a child with disabilities: Parental stress and family functioning over time. American Journal on Mental Retardation 1993;98:207-18.

13. Dyson LL. The experiences of families of children with learning disabilities: Parental stress, family functioning, and sibling self-concept. Journal of Learning Disabilities 1996;29:280-6.

14. Department of Defense. Annual report to the Congressional Defense Committees on plans for the Department of Defense for the Support of Military Family Readiness. Washington, DC: Department of Defense; 2013.

15. Russo TJ, Fallon MA. Helping military families who have a child with a disability cope with stress. Early Childhood Education Journal 2001;29:3-8. 16. Watanabe HK, Jensen PS, Rosen LN, Newby J, Richters JE, Cortês RM. Soldier functioning under chronic stress: Effects of family member illness. Military Medicine 1995;160:457-61. 
17. Reichman N, Corman H, Noonan K. Impact of child disability on the family. Matern Child Health J 2008;12:679-83.

18. Wall S, Kisker EE, Peterson CA, Carta JJ, Hyun-Joo J. Child care for low-income children with disabilities: Access, quality, and parental satisfaction. Journal of Early Intervention 2006;28:283-6,8-91,93-98.

19. Military Compensation and Retirement Modernization Commission. Report of the Military Compensation and Retirement Modernization Commission: Final report. Washington, DC: Military Compensation and Retirement Modernization Commission; 2015.

20. Wheeler BY, McGough D, Godfarb F. The Exceptional Family Member Program: Helping special needs children in military families. In: Rubin A, Weiss EL, Coll JE, eds. Handbook of Military Social Work. Hoboken, NJ: John Wiley \& Sons; 2012:359-81.

21. Aronson KR, Perkins DF. Challenges faced by military families: Perceptions of United States marine corps school liaisons. Journal of Child and Family Studies 2013;22:516-25.

22. Thompson LF, Surface EA. Employee surveys administered online: Attitudes toward the medium, nonresponse, and data representativeness. Organizational Research Methods 2007;10:241-61.

23. Bronfenbrenner Center for Translational Research. Department of Defense Exceptional Family Member benchmark study. Ithaca, NY and Manhattan, KS: Cornell University and The University of Kansas; 2013. 
24. Aronson KR, Caldwell LL, Perkins DF, Pasch KW. Assisting children and families with military-related disruptions: The United States Marine Corps School Liaison Program. Psychology in the Schools 2011;48:998-1015.

25. Astor RA, De Pedro KT, Gilreath TD, Esqueda MC, Benbenishty R. The promotional role of school and community contexts for military students. Clinical Child and Family Psychology Review 2013;16:233-44.

26. Berg KF. Easing transitions of military dependents int Hawaii public schools: An invitational education link. Journal of Invitational Theory and Practice 2008;14:41-55.

27. Sloper P. Facilitators and barriers for coordinated multi-agency services. Childcare, Health and Development 2004;30:571-80.

28. Hayes S, Watson S. The impact of parenting stress: A meta-analysis of studies comparing the experience of parenting stress in parents of children with and without autism spectrum disorder. Journal of Autism \& Developmental Disorders 2013;43:629-42.

29. Ramisch J. Marriage and family therapists working with couples who have children with autism. Journal of Marital and Family Therapy 2012;38:305-16. 30. Taylor NE, Wall SM, Liebow H, Sabatino CA, Timberlake EM, Farber MZ. Mother and soldier: Raising a child with a disability in a low-income military family. Exceptional Children 2005;72:83-99. 
31. Cieslak R, Anderson V, Bock J, Moore BA, Peterson AL, Benight CC. Secondary traumatic stress among mental health providers working with the military:

Prevalence and its work- and exposure-related correlates. Journal of Nervous and Mental Disease 2013;201:917-25.

32. Harrington D, Bean N, Pintello D, Mathews D. Job satisfaction and burnout: Predictors of intentions to leave a job in a military setting. Administration in Social Work 2001;25:1-16.

33. Werner S, Shulman C. Subjective well-being among family caregivers of individuals with developmental disabilities: The role of affiliate stigma and psychosocial moderating variables. Research in Developmental Disabilities 2013;34:4103-14.

34. Grant S, Cross E, Wraith JE, et al. Parental social support, coping strategies, resilience factors, stress, anxiety and depression levels in parents of children with MPS III (Sanfilippo syndrome) or children with intellectual disabilities (ID). J Inherit Metab Dis 2013;36:281-91.

35. Dykens EM, Fisher MH, Taylor JL, Lambert W, Miodrag N. Reducing distress in mothers of children with autism and other disabilities: A randomized trial. Pediatrics 2014;134:e454-e63.

36. Sanders MR. Triple P-Positive Parenting Program: Towards an empirically validated multilevel parenting and family support strategy for the prevention of behavior and emotional problems in children. Clinical Child and Family Psychology Review 1999;2:71-90. 
37. Lester P, Mogil C, Saltzman W, et al. Families overcoming under stress:

Implementing family-centered prevention for military families facing wartime deployments and combat operational stress. Military Medicine 2011;176:19-25. 
Table(s)

Table 1: Family Support Provider Branch

\begin{tabular}{lrrrrl}
\hline Branch & Started & Completed & Invited & Response Rate & Significant Test \\
\hline Army & 67 & 63 & 136 & 46.3 & $\chi 2=8.63 \mathrm{p}<.05$ \\
Air Force & 39 & 34 & 69 & 49.3 & \\
Marine Corps & 30 & 27 & 40 & 67.5 & \\
Navy & 24 & 22 & 33 & 66.7 & \\
Overall & 160 & 146 & 278 & 52.5 & \\
\hline
\end{tabular}


Table 2: Family Support Provider Level of Education

\begin{tabular}{lll}
\hline Highest Level of Education & Frequency & Percent \\
\hline High School Diploma (1) & 1 & 1 \\
Some College (2) & 19 & 12 \\
Bachelor's Degree (3) & 45 & 28 \\
Some Graduate Credits (4) & 9 & 6 \\
Master's Degree (5) & 80 & 50 \\
Doctoral Degree (6) & 4 & 2 \\
Prefer Not to Answer & 2 & 1 \\
Total & 160 & 100 \\
\hline
\end{tabular}


Table 3: Family Support Provider Years at Current Position

\begin{tabular}{lrr}
\hline Number of Years & Frequency & Percent \\
\hline & 31 & 19 \\
Less Than 1 Year (1) & 90 & 56 \\
1 Year to Less Than 5 Years (2) & 20 & 13 \\
5 Years to Less Than 10 Years (3) & 19 & 12 \\
10 Years or More (4) & & \\
& 160 & 100 \\
\hline
\end{tabular}


Table 4: Number of Families on Support Provider Caseload

\begin{tabular}{lrr}
\hline Families on Caseload & N & Percent \\
\hline $1-100(1)$ & 58 & 36 \\
$101-200(2)$ & 26 & 16 \\
$201-300(3)$ & 15 & 9 \\
$301-400(4)$ & 8 & 5 \\
$401-500(5)$ & 11 & 7 \\
$501-986(6)$ & 9 & 6 \\
Prefer not to answer ${ }^{*}$ & 33 & 21 \\
Total & 160 & 100 \\
\hline
\end{tabular}


Table 5: Types of Disabilities Encountered in Past 12 Months

\begin{tabular}{lrc}
\hline Disability & N (Yes) & Percent \\
\hline Autism & 151 & 94 \\
ADHD & 148 & 93 \\
Emotional/Behavioral Disorder & 143 & 89 \\
Speech \& Language Disorders & 142 & 89 \\
Developmental Delay & 141 & 88 \\
Asthma & 140 & 88 \\
Mental Health Problems & 129 & 81 \\
Intellectual Disability & 123 & 77 \\
Multiple Disabilities & 122 & 76 \\
Hearing/Vision Problem & 120 & 75 \\
Physical Disability & 115 & 72 \\
Medical Condition & 81 & 51 \\
Traumatic Brain Injury & 69 & 43 \\
Other & 14 & 9 \\
Total & 160 & \\
\hline
\end{tabular}


Table 6: Caseload Averages in Past 12 Months by Special Need

\begin{tabular}{lcclll}
\hline Disability & Mean & (SD) & N & Min & Max \\
\hline Autism & 45.5 & $(49.6)$ & 127 & 0 & 300 \\
Multiple Disabilities & 44.0 & $(45.0)$ & 127 & 0 & 350 \\
ADD/ ADHD & 40.2 & $(57.4)$ & 124 & 0 & 250 \\
Asthma & 31.2 & $(45.4)$ & 125 & 0 & 200 \\
Developmental Delay & 30.0 & $(36.5)$ & 124 & 0 & 290 \\
Mental Health Problems & 29.2 & $(22.4)$ & 128 & 0 & 400 \\
Emotional/Behavioral Disorder & 29.0 & $(10.5)$ & 123 & 0 & 200 \\
Speech \& Language Disorders & 27.1 & $(46.2)$ & 127 & 0 & 300 \\
Physical Disability & 16.7 & $(45.8)$ & 128 & 0 & 250 \\
Intellectual Disability & 15.2 & $(52.6)$ & 128 & 0 & 109 \\
Medical Condition & 13.9 & $(79.0)$ & 141 & 0 & 500 \\
Hearing/Vision Problem & 6.6 & $(31.5)$ & 131 & 0 & 50 \\
Traumatic Brain Injury & 2.6 & $(7.2)$ & 143 & 0 & 55 \\
Other & 1.6 & $(10.3)$ & 153 & 0 & 100 \\
\hline
\end{tabular}

Note: Sorted by Mean (highest to lowest); Sample size changes due to non-response of the caseload size. If a respondent said no to "type of disability question" the caseload size for that disability $=0$. Mean caseload is reported by number of families who have a dependent with the specific special need. 
Table 7: Other Family Issues Encountered by Family Support Providers

\begin{tabular}{|c|c|c|c|c|c|c|c|c|}
\hline & $\begin{array}{c}\text { Little } \\
\text { or no } \\
\text { extent } \\
(1) \\
\end{array}$ & $\begin{array}{c}\text { Some } \\
\text { extent } \\
(2)\end{array}$ & $\begin{array}{l}\text { Moderate } \\
\text { extent (3) }\end{array}$ & $\begin{array}{c}\text { Great } \\
\text { extent } \\
(4) \\
\end{array}$ & $\begin{array}{l}\text { Very } \\
\text { great } \\
\text { extent } \\
(5) \\
\end{array}$ & $\begin{array}{c}\text { Prefer } \\
\text { not to } \\
\text { answer* }\end{array}$ & Mean & (SD) \\
\hline Educational Concerns & $1 \%$ & $7 \%$ & $16 \%$ & $32 \%$ & $36 \%$ & $7 \%$ & 4.0 & $(1.0)$ \\
\hline Navigating Systems & $3 \%$ & $10 \%$ & $20 \%$ & $22 \%$ & $37 \%$ & $8 \%$ & 3.9 & (1.1) \\
\hline $\begin{array}{l}\text { Child Behavior } \\
\text { Problems }\end{array}$ & $2 \%$ & $13 \%$ & $22 \%$ & $28 \%$ & $28 \%$ & $7 \%$ & 3.7 & (1.1) \\
\hline $\begin{array}{l}\text { Parent Mental Health/ } \\
\text { Stress }\end{array}$ & $1 \%$ & $19 \%$ & $17 \%$ & $30 \%$ & $25 \%$ & $7 \%$ & 3.6 & (1.1) \\
\hline Child Care Issues & $5 \%$ & $16 \%$ & $16 \%$ & $26 \%$ & $29 \%$ & $7 \%$ & 3.6 & $(1.2)$ \\
\hline Medical Problems & $3 \%$ & $14 \%$ & $23 \%$ & $27 \%$ & $25 \%$ & $8 \%$ & 3.6 & (1.1) \\
\hline Parent Education & $7 \%$ & $14 \%$ & $35 \%$ & $22 \%$ & $16 \%$ & $7 \%$ & 3.3 & (1.1) \\
\hline Social Isolation & $12 \%$ & $20 \%$ & $21 \%$ & $24 \%$ & $15 \%$ & $8 \%$ & 3.1 & $(1.2)$ \\
\hline Financial Concerns & $14 \%$ & $19 \%$ & $26 \%$ & $22 \%$ & $13 \%$ & $7 \%$ & 3.0 & $(1.2)$ \\
\hline $\begin{array}{l}\text { Couple/ Family } \\
\text { Conflict }\end{array}$ & $15 \%$ & $35 \%$ & $20 \%$ & $14 \%$ & $8 \%$ & $9 \%$ & 2.6 & (1.1) \\
\hline Job/ School Training & $21 \%$ & $30 \%$ & $18 \%$ & $17 \%$ & $6 \%$ & $9 \%$ & 2.5 & $(1.2)$ \\
\hline Legal Problems & $31 \%$ & $30 \%$ & $20 \%$ & $6 \%$ & $3 \%$ & $10 \%$ & 2.1 & (1.6) \\
\hline
\end{tabular}

Note: *Not included in the average calculation. Sorted by Average (Largest to Smallest). 